\title{
Oration
}

\section{Education in the Indian philosophical context}

\section{Ravin L. Thatte}

Former Head, Department of Plastic Surgery, Lokmanya Tilak Municipal General Hospital and Medical College, Sion, Mumbai - 400 022, India.

Address for correspondence: Dr. R. L. Thatte, Former Head, Department of Plastic Surgery, Lokmanya Tilak Municipal General Hospital and Medical College, Sion, Mumbai - 400 022, India.

$t$ is a privilege and honour to be invited here for this session of continuing medical education. As expected the surroundings are impressive, the organization is impeccable and the formality of the occasion is overwhelming. You have gathered an excellent faculty and a feast awaits those who have come to learn. You might have however made an error in choosing the person for the key note address. I am neither a qualified nor a formally trained plastic surgeon and the manner in which our unit functioned and the volume that it handled I had little time left to teach. And when I had the time my so called students were so tired that they dozed off as I spoke. As a teacher therefore I was virtually non existent. This background should suffice to warn you about my credentials to give this talk. But here I am! A fait acompli ! I will try and do the best out of what I think might have been a bad choice. For some years now I have been dabbling in philosophy and Indian philosophy in particular. It has been a fascinating journey and as all journeys do, this journey too has opened my eyes. I have realized that education is more about atmosphere than of detail, it has more to do with attitude than with form and it is more about the guru than the student.

Unlike what might be a common misconception, the scheme of education in the Indian tradition is founded on the guru not the student. He is the bedrock on which the edifice of education is built. The student is a

Delivered on $10^{\text {th }}$ April 2004 at CME, Armed Forces Medical College, Pune. migratory bird, come to drink, to mould and to grow and pass on. The Guru never dies because he survives through his students and their succeeding generations by what is called a tradition. Notice the nature of the survival of the guru. Unlike education mentioned earlier which is Gurucentric, the Guru's survival is centered on the student. True the student must withdraw from the Guru after a certain time but draws from him throughout his life. The student is a vidyarthi, to mean to come for the purpose of gaining vidya and also to know what vidya is. In the modern context where information overwhelms us and overtakes itself, a question is likely to be posed as to if a Guru can keep pace with this avalanche and deliver the goods or vidya. But the question is very poorly posed. Because vidya is not information. The word has its roots in the Latin word videre from which the words video and vision and idea also arise. In the not so well known description of a Guru given by Dnyaneshwar who breathed his last in Alandi, not far from here, Dnyaneshwar says, "the Guru is like an Anjan for the eyes". The word Anjan has multiple meanings one of which is as follows: "That ability to seek the correct meaning of a word, a phrase or a sentence when multiple meanings are possible." The Anjan called Guru allows you to separate the chaff from the grain or helps you see clearly. The word Anjan also means an ointment, the word having arisen from "to anoint" which in turn in Sanskrit is Deeksha. If you break up the word Deeksha, we have Dik meaning direction or Disha and also Eeksha or eyes. When Deeksha is given only a direction is shown. The act of giving Deeksha is 
not the culmination of a period in which information is stuffed into a student. It is less about a weapon and more about its judicious use. See how pregnant our words are. Words are like a curtain. It needs to be parted to arrive at the truth. The more we understand words, the more careful we become with their use. A mature economy of words constricts speech and reduces the need for articulatory skills. That is why it is often said that his or her grave silence said more in a roomful of arguments. The word grave, means serious, mighty important, dignified, solemn, somber, vital, crucial or heavy. The word engrave also comes from grave, to mean to inscribe on a hard surface. But the most interesting part of the word grave is its Indo European root grr because it is from this root that the word Guru also comes. And it is no coincidence that the largest and most weighty planet in our solar system is called Guru. As an aside let me also mention that the word Aakarshan and Attraction sound similar and Gurutvakarshan is that attraction which is proportionate to the mass that attracts. Indeed the word gravity also comes from the Indo European root Grr. A Guru should attract not by way of his popular appeal, but for his dignity and his weight and having been so attracted a student is etched or engraved with what the guru imparts. The engraving also occurs on a stone on top of a grave which embodies silence.

It cannot be denied that the word "Guru" has been the subject of satire and scorn, ridicule and recrimination in the modern world. The classical example of this is when a prosperous medical practitioner greets the so called lowly full time teacher in a medical college with the greeting: "Here comes the great guru". The statement is loaded unnecessarily with an extra word great because the words great and guru come from the same root. But it also drips with scorn and sarcasm. Shankar Nambudri, the Jagat Guru is on record to have said, "It matters not what your actions do to the world but it matters what they do to yourself." Language is a weapon turned inwards. The same Jagatguru is known to have sent back a student who had come to learn philosophy under him because the student had not learned grammar. We cannot progress unless we can relate and relate we cannot unless we know our words. That lowly full time medical teacher does far greater service by defining and differentiating between an ulcer and a wound, (one comes by way of a molecular process because of disease, the other is a sudden result of an environmental aggression), than those who employ expensive technology to cure patients. I am not knocking on wealth or success but lauding the other, the more fundamental dispenser of education. It is true that the tradition of a Guru has been labeled patriarchial and pompous, dictatorial and draconian, blamed for curbing creativity and creating a servile mindset. But if the gurus were indeed as described here, some of the worlds' greatest philosophical thoughts called Upnishads would not have emerged. Please realize what the word Upnishad means. It simply means "sit here near". In the expanded understood version, that word Upanishad means let us sit with each other and discuss this. But that discussion must be preceded by the didactic which is the art and science of definitions and the meanings in context and consequences in substance. In education there is place for all three, the didactic, the dialogical and then later discovery. One of the current laments of the western world is that their education has become too loose, too freelance. And that is why Bangalore is overtaking Boston via the ether. Could you have imagined Walt Disney's animation being drawn in Pune? To be too freelance is to lance yourself. What is needed, is to leash the mind before freedom can be tasted.

That brings us to the subject "of the mind". I don't want to drown you in the world of philosophy but please realize that in this world of objects, the mind is the subject. The expression, the subject of the mind is a repetition. Be that as may it is often asked if people like Einstein, Newton, Gautam Buddha, Mahavir Jain, Mohammad Paigamber or the Jagadguru Shankar Namboodri had significant gurus. The question is more argumentative than constructive because exceptions and in this instance exceptional people only prove the rule. Most of us or at least a majority require help and this help must be timely. It is not for nothing that the mind is called mercurial because it is difficult to catch even a drop of mercury. The mind has been called faster than lightening, incessant and circular like a tropical storm and as difficult to grasp as a womans' glance. It cannot be cured but can only be cared for. Look how the word education comes. The "cate" in educate originally was "care" and "du" in French is "of the". 
Education is about caring for the mind. The mind is a funny creature. In its raw state it is temptation personified. It drinks through the five holes; eyes, ears, skin, tongue and nose and then orders your limbs. Its presiding deity is reason or intellect or discretion. But that deity has to be installed with care. Too much force will lead to rebellion, to little leads to an anarchical waste. It is the middle path that the Guru must take, the golden mean of Plato, the practical preaching of a Krishna who said, "Kill you may, if you must, but do it after deliberation for a larger cause, not for vengeance, and not with anger, nor out of selfishness". The Guru helps the savage in you to emerge into this world after anointing you with reason. That is what "Smruti" is about. Smruti in Sanskrit is memory, another word for history. Smruti is the result of learning from mistakes. The Smruti talks about Samskar. The word samskar has a total of eighteen meanings as given by Waman Shriram Apte of Ferguson College Pune who completed his monumental work of the Sanskrit English dictionary in 1890 here in Pune and to whom I dedicate this lecture. The meanings of the word samskar are making perfect, moulding, making ready. This is possible only by discipline. The great subject of the Smruti is who should be doing what, at which time and what should be done and how if the said rules are not followed. Punctuality and a dress code, physical exercise and mental concentration, obedience and respect, integrity and loyalty, intellectual freedom but also tradition, self sufficiency and kindred spirit all fall in this category. The armed forces need not be reminded of these. But please realize that it is on this foundation that the temple of education is built. As the Geeta says, "watch your mind and offer it repeated suggestions and watch how it becomes your servant". From a potentially incendiary device to a calm flame, from a hopelessly vulnerable organ to a source of strength. Education encompasses the raw man encountering turmoil, to a stage where a sensible creature approaches the task at hand with peace and determination. The time that you spend with a Guru is a microcosm both of human history and human evolution. From the monkey to a man. The monkey fingers the water to catch the waves on it. Man knows better, that the waves are water itself caused by the wind. The Guru helps your flame by shielding it from the winds of emotion and allows you to see beyond perturbations.
The waves on water are a matter of form. The word form later getting incorporated into information. This is a physical attribute. From information we go to knowledge from the root $k n$ or $g n$ also later to become gnyan or dnyan in Sanskrit or Marathi. This is about how waves form on water, that water is a substrate, that a wind blows and then the water crests, leading to waves. This is a clinical diagnosis. Notice the root $g n$ in Diagnosis as well. Further, we can look around and surmise if the wind will continue to blow and then arrive at a certain prognosis as well. But realization is still further. What is wind? What is water? Those are the questions that need to be answered in realisation. In modern scientific terms they are mere masses of energy packed as atoms and what are atoms but vast empty spaces in which very small subatomic things roam. Sometimes as waves and sometimes as matter. That is the reality as far as we know today. Notice that the word realization has the word real in it. In clinical parlance (1) what does the patient say, (2) what is he showing, (3) what does the clinician feel and see, (4) what does the clinician think, (5) what would he like to do are the steps of the ladder to reach just below the terrace. It is on the terrace that you encounter the person again, the full human being, the so called patient who is impatient. You are the surgeon and therefore must be patient. The guru helps you reach the terrace and leaves you there. It is upto you to pick up the bow and the arrow. Like Shrikrishna tells Arjun, "Enough of my advice, please exercise your reason and arrive at a judgment. In this judgment, fear for self must play no part. You must fear for the patient but not for yourself."

Logic then is the terrace where you must deal with information. The word Nyaymurti in Sanskrit is a good example of how the Sanskrit language and Indian philosophy thinks about logic. In Sanskrit the word Nyay does not mean justice. It means logic. A Nyaymurti is therefore an embodiment of logic. And the word nikal patra means a letter of conclusion not as is popularly held "the arrival at truth". Logic is a weapon with which we cleave the matter at hand to inspect it. Much before Western philosophy or science extolled on the virtues of Oram's Razor, Dnyaneshwar had described the Nyay School of logical philosophy as an axe and Kanad's atomic hypothesis - as a hook. Kanad was a 
contemporary of the Greek Democritus who too was explaining the world on the basis of atoms. The Guru teaches you to use logic to cleave a problem and then look at it in its minutest detail. Next in order is the Sankhya Doctrine of Kapil who analysed the mind matter complex and next comes Patanjali who described how the complex can be disturbed and how it is to be cared for. It is a two way street this mind matter complex. You can abuse matter by taking in improper material and disturb the mind or vice versa where you can abuse your mind to produce material disturbance. The line between the two is very thin because matter after all is a condensate of energy, something that modern physics has now confirmed. The word Yog is from the root Yuj to mean to join or to harness. Notice that it is no different from the word Yoke in English which is employed for animals. The animal in man requires to be yoked and this is what the Guru does via logic, detail, system, and harmony, the last being the Patanjal Yog Sutra. The word sutra coming from suta or a thread.

On the background that a particular science is to be taught in this meeting what I have said might appear rather fuzzy or vague. To those who have come here to learn of the intricacy of a perforator flap or the latest in free flap transfer or neural outflows via the brachial plexus I offer my apologies. I impose upon you and disappoint you but I had no choice. I tried to be difficult, chose an unlikely and unpopular subject but the hosts insisted. This is a classic case of "Aa Bail Muze Mar"!! But I also come here with an ulterior and probably also a honest motive. I was and continue to be apprehensive of too much technique and technology. True, life has been revolutionized by the pair. Information is at hand and more importantly in the hands of those who were forbidden to use it or unable to make use of it. Communication is swift. Mukund Thatte and Milind Wagh, two of my students who are organizing the Asia-Pacific meeting have the world of Plastic surgeons in their palms and on their fingertips. The speed with which we drive on this highway is awesome and as a result we are inundated with information. Sometime ago I asked an editor of an important Indian daily newspaper if looking at all this information leaves him anytime for reflection, introspection and contemplation so that he can put forth a cogent view as to what is happening around him? He took it as criticism and an indicment imagining that it was a loaded question. I don't blame him. The cap fit him and it was a cap that hurt him. Like the well known question as to "when did you stop beating your wife", this question too can be answered only by saying 'I am not married' and that answer too might be false.

I am thrilled by what the past trainees in my unit are doing but also worried that they are so used to the information highway, so welded to their machines, have so walked into the web of the material world that they are left with no time to think. Imagine a student with high grades in $10^{\text {th }}$ and $12^{\text {th }}$ standarts then the CET, then 5 years of medicine, then another three in general surgery followed by three more years of a superspeciality. At all these levels his intelligence is a slave to his career. Then he comes out to peer through a microscope for hours on end, or banging in front of a computer screen and as if this were not enough, such is the state of our public institutions that he must then become an entrepreneur, a manager, a financier, bit of a lawyer and also cope with labour problem in his own hospital which alone he thinks will give him his dues for the labour he has undergone. To me this is a waste though on the surface all this looks full of wonder. Before my eyes plastic surgery in India has undergone a sea change. Young, bursting, headstrong, enthusiastic, energetic, intelligent young men and women detached from teaching hospitals have now emerged on the scene. The question is do they have time to think. I have ticked 7 names on the left side of CME faculty as the victims and culprits. What solutions do I offer? To turn back to Gautam's Nyaydarshan I have presented what is the Poorva Paksha or the preamble or the problem. The next step is wad and pratiwad or thesis and antithesis and then will emerge the uttarpaksha or synthesis. But in order to do this the young men and women whom I address must agree that the Poorva Daksha or a problem exists. Then they must gather and like in the word Upnishad must say to each other let us sit near each other and talk this over. They need to meet in what the Church calls a retreat. A retreat from their world of action to one of contemplation. In the famous words of Arjun penned by Dnyaneshwar from the fourth chapter of the Geeta: 
Thatte RL

\author{
What is best \\ I still don't get \\ Should I engage the world \\ Or just contemplate \\ The answer given is \\ Without a thought \\ To the basis of your work \\ Life is a waste \\ And has no worth.
}

To those who have come to teach and to learn I just would like to say this: Work intoxicates us as it should, that is natural, but we must also have productive interludes of sobriety! The country now is poised on the threshold of an unknown future like never before in the last 1000 years. You can see the signs, our journal is an example of this impending change. You chaps have strong shoulders and intelligent brains. The question is will you seek wisdom in your professional life, your personal attitudes and benefit the current and future generations?

Thank you for paying attention. 